Edunomika - Vol. 04, No. 01 (Februari 2020)

\title{
PENGARUH GAYA KEPEMIMPINAN, SKILL DAN ATTITUDE TERHADAP KINERJA KARYAWAN \\ (Studi pada karyawan Hotel Indah Palace di Tipes Surakarta)
}

\author{
Putri Ayu Adika', Ida Aryati DPW'2, Istiqomah ${ }^{3}$ \\ Fakultas Ekonomi, Program Studi Manajemen \\ Universitas Islam Batik Surakarta (UNIBA) \\ e-mail: putriadika427@gmail.com
}

\begin{abstract}
The Influence of Leadership Style, Skill, and Attitude on Employee Performance (Study of Indah Palace Hotel Employees in Tipes Surakarta). Thesis Management Study Program (S1). Surakarta Islamic Muslim University 2020. The purpose of this study wes to determine the effect of Leadership Style, Skill, and Attitude on Employee Performance (Study of Indah Palace Hotel Employees in Tipes Surakarta). This research uses quantitateve research. The population is all 40 employees of the Indah Palace Hotel Surakarta. The number of samples used was 40 respondents. The sampling technique uses non probability sampling method with saturated sampling approach. The data analysis technique used for this study is using multiple linear regression. The results of the study show that the F test influences the Leadership Style, Skill, and Attitude simultaneously and significantly influences the performance of employees at the Indah Place Hotel in Tipes Surakarta. $T$ test results showed that the Leadership Style had a positive and significant effect on employee performance at the Indah Palace Hotel Surakarta, Skills had a positive and significant effect on employee performance at the Indah Palace Hotel Surakarta, and Attitude had a positive and significant effect on employee performance at the Indah Palace Hotel Surakarta. The coefficient of determination shows the variables of Leadership Style, Skill, and Attitude have an influence of 72,9\% on the variable Employee Performance in the Indah Palace Hotel Surakarta, the rest of 27,1\%. The most dominant influence on the performance of employees of the Indah Palace Hotel Surakarta is that the Leadership Style variable has the biggest t count, which is 4,287.
\end{abstract}

Keywords: Leadership Style, Skill, and Attitude, Employee Performance

\section{PENDAhuluan}

Sumber daya manusia merupakan keterbukaan dalam penggalan suatu instansi. Sumber daya manusia membentuk pondasi amat kokoh untuk menyungsang keberhasilan suatu perusahaan. Instansi membentuk salah satu cara institusi untuk melaksanakn kegiatan tata usaha manajemen antara lain perangkaan, koordinasi, ajaran. Dalam hal ini instansi hendak memeriksa sumber daya manusia yang berbobot dan meningkatkan memernkan sosok yang berlimpah akan kompetensi sehingga bisa mendorong kinerja instansi ke depannya (Susilo 2018:61).

Kemajuan hotel terjadi amat tinggi pertama di 5 tahun terakhir, kemajuan terbilang akan terus berjalan bersama pertambahan pariwisata yang terus tumbuh dan muncul di Indonesia. Tingkat kediaman hotel di Indonesia menjalin peningkatan dari 52,27\% menjadi 56,73\% pada bulan Juni 2019. 
Hotel bukanlah sesuatu hal yang berlebih-lebihan karena semua orang dapat menginap di hotel karena banyak jenis dari yang full service atupun hotel budget. Pengunjung dapat memilih hotel sesuai dengan keinginan. Konsumen hotel tidak harus melalui telepon atau datang langsung ke hotel. Kurang lebih tahun belakangan ini banyak aplikasi ponsel ataupun situs internet yang mempersiapkan layanan pemesanana kamar hotel. Hal tersebut merupakan gaya kemajuan teknologi sehingga memudahkan pengunjung untuk memilih hotel sesuai dengan kebutuhan tanpa harus datang dan bertanya kepada resepsionis tiap hotel. Kota Surakarta mempunyai hotel yang layak banyak jumlahnya. Sehingga perlu mendapatkan pengunjung ada beberapa cara hotel untuk simpatik calon pengujung untuk menginap mulai memberikan potongan harga, memberikan fasilitas lebih atau juga menjaga mutu pelayanan hotel agar pengunjung yang datang akan menjadi pelanggan setia yang akan kembali lagi untuk menginap karena puas dengan pelayanan hotel yang telah di berikan.

Berdasarkan pada uraian di atas, riset layak untuk dilakukan guna melihat kinerja karyawan di Hotel Indah Palace memakai judul "Pengaruh Gaya Kepemimpinan, Skill dan Attitude Terhadap Kinerja Karyawan.

Penelitian ini bertujuan untuk menganalisis pengaruh:

1. Gaya Kepemimpinan, Skill, dan Attitude Terhadap Kinerja Karyawan di Hotel Indah Palace di Tipes Surakarta.

2. Gaya Kepemimpinan Terhadap Kinerja Karyawan di Hotel Indah Palace di Tipes Surakarta.

3. Skill Terhadap Kinerja Karyawan di Hotel Indah Palace di Tipes Surakarta.

4. Attitude Terhadap Kinerja Karyawan di Hotel Indah Palace di Tipes Surakarta.

\section{LANDASAN TEORI}

1) Kinerja Karyawan

Kemampuan karyawan adalah prestasi kerja yang mempunyai jumlah yang diperoleh seseorang pekerja dalam melaksanakan pekerjaanya singkron dengan tanggung jawab untuk diberikan kepada pegawai Mangkunegara (2017: 9).

2) Gaya Kepemimpinan

Gaya kepemimpinan merupakan sifat atau desain, menjadi perpaduan dari ajaran, trampil, ciri, keputusan, kadang diterapkan untuk pemimpin saat berupaya mempengaruhi kinerja bawahannya (Uhing et al 2018:6).

3) Skill

Kemampuan membutuhkan ilmu yang diperoleh melalui training dan keahlian dalam melaksanakan sebagaian pekerjaan sehingga orang berpengalaman yang bekerja lebih bernilai dan lebih cepat (Wulan et al 2018:7).

4) Attitude

Sikap (Attitude) melambangkan kesiapan bagi seseorang dalam bertindak sebagai didalam hal-hal tertentu (Sarwono, 2000)

\section{METODOLOGI}

Bentuk penelitian ini menggunakan penelitian kuantitatif. Tempat penelitian ini di Hotel Indah Palace di Tipes Surakarta dilakukan mulai Oktober 2019 - Februari 2020. Populasi penelitian ini adalah seluruh pegawai Hotel Indah Palace di Tipes Surakarta dan semua dijadikan sampel yang berjumlah 40 orang. Teknik sampling jenuh digunakan dalam penelitian ini. Dimana sampling jenuh mengambil dari seluruh populasi. Penelitian ini menerapkan analisis linear berganda. 


\section{Analisis Data dan Pembahasan}

1) Deskripsi Responden

Jenis Kelamin

\begin{tabular}{|c|c|c|}
\hline Jenis Kelamin & Jumlah & $(\%)$ \\
\hline Laki-aki & 25 & $75 \%$ \\
\hline Perempuan & 15 & $25 \%$ \\
\hline Total & 40 & 100,00 \\
\hline
\end{tabular}

Jenis kelamin karyawan dari hasil pengumplan data kuesioner didapatkan bahwa pegawai laki sebanyak 25 (75\%) dan pegawai perempuan sebanyak $15(25 \%)$.

2) Analisi Data

a. Uji Instrumen

1) Uji Validitas

\begin{tabular}{|c|c|c|}
\hline Butiran Pertanyaan & $\begin{array}{c}\text { Total Person } \\
\text { Correlation }\end{array}$ & Keterangan \\
\hline Kinerja Karyawan & & Valid \\
Pertanyaan 1 & 0,577 & Valid \\
Pertanyaan 2 & 0,694 & Valid \\
Pertanyaan 3 & 0,515 & Valid \\
Pertanyaan 4 & 0,691 & Valid \\
Pertanyaan 5 & 0,574 & Valid \\
Pertanyaan 6 & 0,569 & Valid \\
\hline Gaya Kepemimpinan & & Valid \\
Pertanyaan 1 & & Valid \\
Pertanyaan 2 & 0,558 & Valid \\
Pertanyaan 3 & 0,625 & Valid \\
Pertanyaan 4 & 0,319 & Valid \\
Pertanyaan 5 & 0,676 & Valid \\
Pertanyaan 6 & 0,746 & Valid \\
\hline Skill & & Valid \\
Pertanyaan 1 & 0,848 & Valid \\
Pertanyaan 2 & 0,915 & Valid \\
Pertanyaan 3 & 0,921 & Valid \\
Pertanyaan 4 & 0,914 & Valid \\
Pertanyaan 5 & 0,898 & Valid \\
Pertanyaan 6 & 0,584 & Valid \\
\hline Attitude & & Valid \\
Pertanyaan 1 & 0,940 & Valid \\
Pertanyaan 2 & 0,922 & Valid \\
Pertanyaan 3 & 0,920 & Valid \\
Pertanyaan 4 & 0,866 & Valid \\
Pertanyaan 5 & 0,794 & Valid \\
Pertanyaan 6 & 0,798 & Valid \\
\hline
\end{tabular}

Berdasarkan tabel di atas, dari 24 butiran kuesioner yang dijalankan pada 40 orang dinyatakan valid karena $r_{\text {hitung }}$ pada semua pertanyaan lebih besar dari $r_{\text {tabel }}\left(r_{\text {hitung }}>\right.$ 0,312 ).

2) Uji Reabilitas

\begin{tabular}{|c|l|c|c|c|}
\hline Io & Variabel & $\begin{array}{l}\text { Nilai Cronbach's } \\
\text { Alphu }\end{array}$ & Batasan & Keterangan \\
\hline 1. & Kinerja Karywan & 0,655 & 0,600 & Reliabel \\
2. & Gaya Kepemimpinan & 0,708 & 0,600 & Reliabel \\
3. & Skill & 0,914 & 0,600 & Reliabel \\
4. & Attitude & 0,938 & 0,600 & Reliabel \\
\hline
\end{tabular}


Nilai reliabilitas variabel Kinerja Karyawan (Y) sebesar 0,655. Gaya Kepemimpinan $\left(\mathrm{X}_{1}\right)$ 0,708. Skill $\left(\mathrm{X}_{2}\right)$ 0,914 lebih dari 0,600. Attitude $\left(\mathrm{X}_{3}\right)$ sebesar 0,938. Dan nilai variabel di atas > 0,600 dapat disimpulkan instrument pada variabel Kinerja Karyawan, Gaya Kepemimpinan, Skill, dan Attitude dinyatakan reliabel.

b. Uji Koefisien Determinasi $\left(\mathrm{R}^{2}\right)$

Adjusted $R$ Square adalah 0,729 . Berarti presentase sumbangan pengaruh gaya kepemimpinan, skill, dan attitude terhadap kinerja karyawan adalah 72,9\%. Sisanya $27,1 \%$ faktor-faktor lain diluar model yang diteliti.

c. Analisis Linier Berganda

Persamaanya regresi sebagai berikut:

$\mathrm{Y}=10,040+0,385\left(\mathrm{X}_{1}\right)+0,191\left(\mathrm{X}_{2}\right)+0,078\left(\mathrm{X}_{3}\right)+\mathrm{e}$

Interprestasi analisi linier berganda sebagai berikut:

1) Konstanta $\mathrm{a}=10,040$

Gaya kepemimpinan, skill, dan attitude tidak ada kenaikan atau nilainya adalah 0 , kinerja karyawan nilainya sebesar 10,040.

2) Koefisisen $b_{1}=0,385$

Adalah gaya kepemimpinan ditingkatkan 1 ukuran, nilai gaya kepemimpinan adalah 0,385 ukuran atas asumsi variabel selain gaya kepemimpinan yaitu skill dan attitude bernilai tetap (konstan).

3) Koefisien $b_{2}=0,191$

Adalah jika skill ditingkatkan 1 ukuran, nilai skill naik 0,191 ukuran atas asumsi variabel selain skill yaitu gaya kepemimpinan dan attitude bernilai tetap (konstan).

4) Koefisien $b_{3}=0,078$

Adalah jika attitude ditingkatkan 1 ukuran, nilai attitude naik 0,078 ukuran atas asumsi variabel selain attitude yaitu gaya kepemimpinan dan skill bernilai tetap (konstan).

d. Uji Asumsi Klasik

1) Uji Normalitas

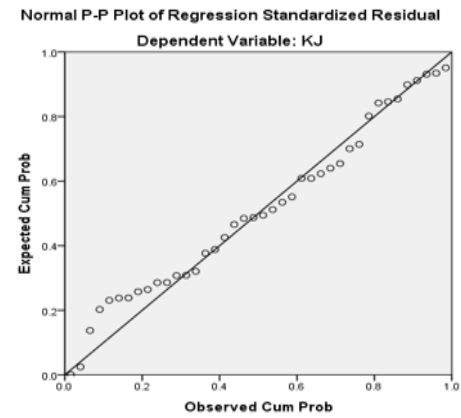

Diketahui bahwa gambar di atas menyebar mengukuti baris diagonal, data terdistribusi bersama-sama normal, bentuk regresi telah mnduga asumsi normalitas.

2) Uji Multikolonieritas 


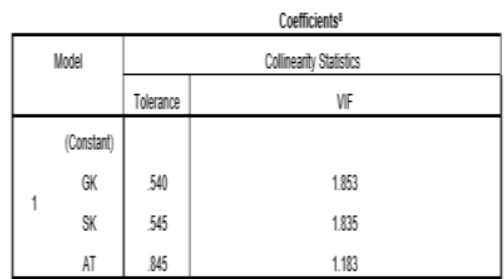

Semua variabel nilai Torelance sebesar $>0,10$ nilai VIF $>10$ bisa disimpulakan bahwa semua variabel tidak terjadi terjadi Multikolinearitas.

3) Uji Heterokedastisitas

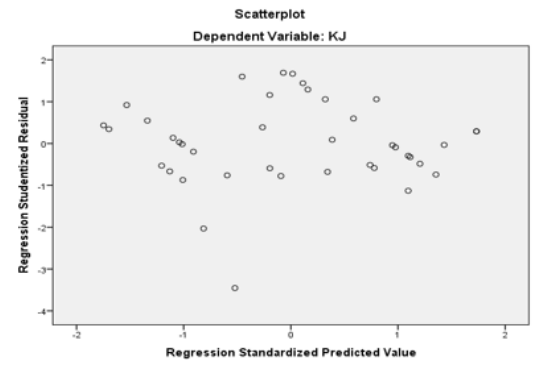

Scatterplot gambar di atas bukan membentuk model khusus (menyebar), maka pola regresi pada obsevasi tidak terjadi Heteroskedastisitas.

e. Uji Hipotesis

1) Uji Simultan $(F)$

Analisis uji $\mathrm{F}$ diperoleh $f_{\text {hitung }}>f_{\text {tabel }}(38,896>3,25)$ signifikannya $(0,000<0,05)$ $H_{o}$ ditolak. Gaya Kepemimpinan $\left(\mathrm{X}_{1}\right)$, Skill $\left(\mathrm{X}_{2}\right)$, dan Attitude $\left(\mathrm{X}_{3}\right)$ positif dan signifikan.

2) Uji Persial (t)

a) Pengujian variabel Gaya Kepemimpinan $\left(\mathrm{X}_{1}\right)$

Diketahui nilai $t_{\text {hitung }}$ adalah sebesar 4,287. Sedangkan $t_{\text {tabel }}$ di dapatkan dari rumus $t_{\text {tabel }}=(0,05 / 2 ; \mathrm{n}-\mathrm{k})$, sehingga $(0,025 ; 40-3)$ atau $(0,025 ; 37)$ pada taraf signifikan $=$ $5 \% t_{\text {tabel }}$ 2,026. Dengan demikian $t_{\text {hitung }} 4,287>t_{\text {tabel }} 2,026$ berarti Ho diterima. Pada nilai signifikan memiliki nilai $0,000<0,05$ gaya kepemimpinan secara signifikan terhadap kinerja.

b) Pengujian variabel Skill $\left(\mathrm{X}_{2}\right)$

Diketahui nilai $t_{\text {hitung }}$ adalah sebesar 3,085. Sedangkan $t_{\text {tabel }}$ di dapatkan dari rumus $t_{\text {tabel }}=(0,05 / 2 ; \mathrm{n}-\mathrm{k})$, sehingga $(0,025 ; 40-3)$ atau $(0,025 ; 37)$ pada taraf signifikan $=$ $5 \% t_{\text {tabel }}$ 2,026. Dengan demikian $t_{\text {hitung }} 3,085>t_{\text {tabel }} 2,026$ berarti Ho diterima. Pada nilai signifikan memiliki nilai $0,004<0,05$. Skill secara signifikan kinerja.

c) Pengujian variabel Attitude $\left(\mathrm{X}_{3}\right)$

Diketahui nilai $t_{\text {hitung }}$ adalah sebesar 2,263. Sedangkan $t_{\text {tabel }}$ di dapatkan dari rumus $t_{\text {tabel }}=(0,05 / 2 ; \mathrm{n}-\mathrm{k})$, sehingga $(0,025 ; 40-3)$ atau $(0,025 ; 37)$ pada taraf signifikan $=$ $5 \% t_{\text {tabel }}$ 2,026. Dengan demikian $t_{\text {hitung }} 2,263>t_{\text {tabel }} 2,026$ berarti Ho diterima. Pada nilai signifikan memiliki nilai $0,030<0,05$. Attitude secara signifikan terhadap kinerja. 


\section{Pembahasan}

Penelitian terhadap karyawan yang bekerja di Hotel Indah Palace di Tipes Surakarta menerangkan gaya kepemimpinan, skill, dan attitude mempengaruhi kinerja karyawan.

1) Gaya kepemimpinan terhadap kinerja karyawan

Uji regresi berganda menunjukkan $t_{\text {hitung }} 4,287>t_{\text {tabel }} 2,026$ dan signifikan 0,000<0,05. Gaya kepemimpinan signifikan terhadap kinerja dan tidak memiliki dampak kinerja karyawan.

2. Skill terhadap kinerja karyawan

Uji regresi berganda menunjukkan $t_{\text {hitung }} 3,085>t_{\text {tabel }} 2,026$ dan signifikan $0,004<0,05$. Skill signifikan terhadap kinerja dan tidak memeiliki dampak kinerja karyawan.

3) Attitude terhadap kinerja karyawan

Uji regresi berganda menunjukkan $t_{\text {hitung }} 2,263>t_{\text {tabel }} 2,026$ dan nilai signifikan $0,030<0,05$. Attitude signifikan terhadap kinerja dan tidak memiliki dampak kinerja karyawan.

4) Gaya kepemimpinan, skill, dan attitude terhadap kinerja karyawan Uji regresi Uji $f_{\text {hitung }}>f_{\text {tabel }}(35,896>3,25)$. Nilai signifikan $(0,000<0,05)$. Gaya Kepemimpinan $\left(\mathrm{X}_{1}\right)$, Skill $\left(\mathrm{X}_{2}\right)$, dan Attitude $\left(\mathrm{X}_{3}\right)$ berpengaruh positif dan signifikan terhadap Kinerja Karyawan (Y).

\section{KESIMPULAN}

Hasil penelitian di atas dapat disimpulkan

a. Gaya Kepemimpinan, Skill, dan Attitude terhadap Kinerja Karyawan di Hotel Indah Palace di Tipes Surakarta terdapat pengaruh positif dan signifikan.

b. Gaya kepemimpinan $\left(\mathrm{X}_{1}\right)$ berpengaruh terhadap kinerja karyawan di Hotel Indah Palace di Tipes Surakarta.

c. Skill $\left(\mathrm{X}_{2}\right)$ berpengaruh terhadap kinerja karyawan di Hotel Indah Palace di Tipes Surakarta.

d. Attitude $\left(\mathrm{X}_{3}\right)$ terhadap kinerja karyawan di Hotel Indah Palace di Tipes Surakarta.

\section{DAFTA PUSTAKA}

Rasid, Z., Tewal, B., \& Kojo, C. (2018). Pengaruh Hard Skill dan Soft Skill Terhadap Kinerja Karyawan Perum Damri Manado. Jurnal EMBA: Jurnal Riset Ekonomi, Manajemen, Bisnis dan Akuntansi, 6(2).

Budiman, N. P., Saerang, I. S., \& Sendow, G. M. (2016). Pengaruh Kompetensi, Motivasi, dan Disiplin Kerja Terhadap Kinerja Karyawan (Studi Pada PT. Hasjrat Abadi Tendean Manado). Jurnal EMBA: Jurnal Riset Ekonomi, Manajemen, Bisnis dan Akuntansi, 4(3).

Budiyono. (2019). Motivation Of Work, Organizational Culture, And Organizational Commitment Towards Work Productivity Lecturers And Employees Of Economics College AAS Surakarta (STIE AAS Surakarta). Humanities \& Social Sciences Reviews, 7(5), 226-236.

Fajrin, I. Q., \& Susilo, H. (2018). Pengaruh Gaya Kepemimpinan terhadap Kinerja Karyawan dengan Motivasi Kerja sebagai Variabel Intervening (Studi pada Karyawan Pabrik Gula Kebon Agung Malang). Jurnal Administrasi Bisnis, 61(4), 117-124. 
Makutika, D. H. P., \& Uhing, Y. (2018). Pengaruh Gaya Kepemimpinan, Kesejahteraan Dan Komunikasi Terhadap Kepuasan Kerja Karyawan Pada Pt. Bank Sulutgo Cabang Tahuna. Jurnal EMBA: Jurnal Riset Ekonomi, Manajemen, Bisnis dan Akuntansi, 6(4).

Untari, N. P., Sudarwati, S., \& Wulan, I. A. D. P. (2018). Analisis Attitude, Knowledge Dan Skill Terhadap Kinerja Di Hotel (Studi Tentang Kinerja Alumni Victoria Hotel School). Jurnal Manajemen dan Keuangan, 7(1), 25-31. 